\title{
POLITICA, FINANZAS E INFRAESTRUCTURA COMERCIAL: VALENCIA Y MALLORCA EN LA PRIMERA MITAD DEL SIGLO XV
}

\begin{abstract}
SUMARIO
1. Introducción - 2. La creación del «Col-legi de la Mercaderia»- 3. La quiebra financiera del reino de Mallorca - 4. La política de obras públicas en Valencia - 5. Problemas defensivos - 6. Problemas financieros en Valencia - 7. Crisis financiera en Mallorca - 8. La construcción de la Lonja de Palma - 9. Abandono de las instalaciones portuarias de Mallorca - 10. Conclusión.
\end{abstract}

\section{INTRODUCCIÓN}

La primera mitad del siglo XV en Mallorca es una etapa compleja; hay una notable actividad del comercio durante las primeras décadas, estimulada por la política mediterránea de Alfonso $\mathrm{V}$, pero este relativo auge coincide con la crisis financiera de la Universidad -desde 1392 un catalán administra la deuda pública de la Universidad, y desde 1405 los ingresos de ésta se destinan al pago de pensiones- y con el conflicto social de foráneos y ciudadanos.

En este contexto, pocas esperanzas quedaban para una política de infraestructura comercial; sin embargo, aprovechándose el lapso de tiempo, entre 1425 y 1431 , en que se decretó el cese del pago de pensiones de deuda a catalanes, se procedió a la construcción de la Lonja, única realización importante que se registra en el período mencionado.

La situación de Valencia es bastante distinta: el endeudamiento público del municipio es todavía moderado durante la primera mitad del siglo, la economía es próspera y los conflictos agrarios son inexistentes, debido al control estricto de los musulmanes. Estos hechos determinan que el municipio de Valencia pueda atender una política de obras públicas y una mejora de la infraestructura comercial.

\section{LA CREACIÓN DEL «COL·LEGI DE LA MERCADERIA»}

De 1403 datan las primeras informaciones sobre la organización del Col.legi de la Mercaderia de Mallorca ', organismo creado por Juan I en 1394 a solicitud de los

1 F. SEvillano COLOM y J. POU, Historia dal puerto de Palma de Mallorca, Palma de Mallorca, 1974, p. 456-458, nota 316 y p. 204-209. 
síndicos de los reinos de Valencia y Mallorca, de las ciudades de Barcelona, Tortosa y Perpiñán.

Al no obrar el documento sancionado por dicho rey, nuestro conocimiento de las características y objeto de esta institución se reduce básicamente a los siete capítulos que el 11 de mayo de 1403 fueron tomados como punto de referencia para proceder a elegir los distintos cargos, que el privilegio real contemplaba. De ahí que la mayor parte del documento citado se refiera a procedimiento electoral, en tanto que el objetivo del organismo, las competencias de sus elementos rectores y su financiación no aparecen relacionados. Del mencionado documento fragmentario se deducen, en síntesis, tres puntos básicos:

a) En Mallorca, dicho organismo estaría integrado por dos deffenedors, un clavario y veinte consejeros mercaderes.

b) El procedimiento electoral combinaba los sistemas de designación y de elección; los Jurados de la ciudad nombraban una comisión de prohombres, uno por cada estamento, y ambos conjuntamente elegían a los veinte consejeros; finalmente, estos últimos elegían, per via de escrutini, los dos deffenedors.

c) El Col.legi de la Mercaderia tenía asignadas ciertas funciones administrativas sobre los impuestos comerciales, pero no estaba autorizado a realizar ningún cambio en el sistema impositivo vigente sin los votos del Consell General.

Al final de esta primera década, otro documento nos informa de la evolución institucional del Col.legi de la Mercaderia. El documento en cuestión no lleva fecha, aunque se remite a una ordenanza de 1409, dictada por Martín el Humano ${ }^{3}$. Dicha ordenanza real es tomada como marco jurídico para el procedimiento electoral, que resulta ser muy distinto del prescrito en 1403 . En efecto, ya no son los Jurados sino los consejeros del Col.legi quienes tienen el control de los órganos de esta institución. Los consejeros se renuevan sólo parcialmente cada año, por el sistema de cooptación, y es la asamblea de los veinte consejeros la que elige a los dos deffenedors.

Además, dicho documento incluye un acta de acuerdos, entre los que se encuentra el dotar de fondos al Col.legi; para ello se creaba una tasa, a pagar por todos los asociados, sobre el tráfico de mercancías entrants e exints. Su importe se fijaba en dos dineros por cada diez libras. En suma, el documento de 1409 ha permitido crear ya un organismo autónomo, con disposición de rentas propias.

\section{LA QUIEBRA FINANCIERA DEL REINO DE MALLORCA}

Como hemos señalado, desde 1392 los ingresos fiscales del reino eran administrados por un catalán, ya que la mayor parte de la deuda pública se encontraba colocada en Barcelona 4 .

Sin embargo, era frecuente que la Universidad pagara con retraso, e incluso con mucha demora, las pensiones de la deuda; esto se debía a contingencias, como las

2 A. DE CAPMANY, Memorias bistóricas sobre la marina, comercio y artes de la antigua ciudad de Barcelona, Barcelona, Cámara Oficial de Comercio y Navegación, 1963, II, p. 401-402.

3 F. SeVillano Colom y J. POU, Op. cit., p. 459-460.

4 A. SANTAMarín, El reino de Mallorca en la primera mitad del siglo XV, Palma de Mallorca, 1955, p. 4445. 
sequías, que determinaban la importación de trigo, a necesidades defensivas y a un cierto nivel de corrupción, inducido por las luchas de banderías. En ocasiones, la Universidad procedía a una rebaja de los intereses de la deuda, por lo que las relaciones entre los acreedores y la Universidad distaban de ser cordiales.

Lo peor fue cuanto todos los factores indicados confluyeron. En 1395, uno de los bandos pagó su permanencia en el poder entregando 100.000 florines al rey y cargando esta cantidad en el debe de las finanzas municipales. En 1403 se producen lluvias torrenciales que destruyen la ciudad baja y comienza un ciclo de malas cosechas, a las que se une una epidemia en 1404. A finales de este mismo año se rebajan los intereses de la deuda a un 6,6\%, y a pesar de ello la Universidad no puede atender los pagos?

En consecuencia, los procuradores de los acreedores proceden a instar ejecuciones contra particulares de Mallorca en calidad de responsables subsidiarios, y ante la situación de emergencia se firma el llamado Contrato Santo en 1405. Sus puntos básicos eran la consignación de todos los impuestos al pago de los intereses y la prioridad de pago a los acreedores barceloneses. La Universidad sólo podría disponer, para sus gastos ordinarios y extraordinarios, de 3.450 libras anuales ${ }^{6}$.

En esta coyuntura, todo proyecto de mejora infraestructural resultaba impensable, ya que apenas se podía atender al mantenimiento de las instalaciones existentes.

En 1406, se descargaban en el muelle mil piezas de piedra con destino a la obra del palacio mayor de Barcelona '. No consta en este momento protesta alguna sobre el particular, pese a las prohibiciones existentes sobre el tema. Sin embargo, cuatro años después los mercaderes piden al Consell General que, en evitación de que el muelle artificial se destruescha per la mar, se asigne a su reparación el impuesto llamado de entrades e exides de navilis. Contestación de los Jurados: Lo dit dret dels navilis es consignat als censals e no si pot retochar en alguna manera "; ahora bien, autorizaban la realización de las obras necesarias.

Por la misma época, en 1407, el Consell General decide comprar unas casas para habilitarlas como Sala o casa de los Jurados y Consell General. La falta de fondos les impide, sin embargo, realizar la operación, pese a la opción de compra. Pasados tres años, el propietario de dichas casas reclamaba una indemnización de 150 libras por incumplimiento del pacto acordado '.

La capilla-lazareto de San Nicolás de Portopí, construida en las primeras décadas del siglo XIV, aparece fuera de servicio en 1410; sus instalaciones eran utilizadas por los Jurados como arsenal ${ }^{10}$.

3 E. AGUILÓ, Rubrica dels llibres de pregons, «BSAL», IX (1901-1902), p. 275.

6 A. SANTAMARÍA; Op. cit., p. 47-48.

7 J. MUNTANER, Miscelánea de documentos, «BSAL», XXX (1947- 1952), p. 80-81.

8 ARM, AGC 2, fol. $50 \mathrm{v}$.

9 Id, id, fol. 374.-37 v. La Juradía y el Consell General de Mallorca ocupaban varias dependencias del hospital de San Andrés en régimen de alquiler.

10 ARM, AGC, 2, fol. $46 \mathrm{r}$. 


\section{LA POLÍtica de ObRAS PÚblicas eN VALENCIA}

Mientras Mallorca quedaba amordazada por su quiebra financiera, Valencia despliega durante la primera mitad del siglo XV una vasta política de obras públicas, continuidad de las realizadas en el siglo anterior (construcción de nuevas murallas en 1356-1370, Casa de la Ciudad, Lonja de mercaderes, ampliada entre 1389-1392, y Consulado de Mar). Pero quizás el legado más significativo del siglo XIV fue la junta de murs e valls que, aparte de las defensas de la ciudad, tenía a su cuidado las acequias, puentes y caminos, financiándose con un tributo que gravaba la compraventa de trigo en el almudín ".

Durante la primera mitad del siglo XV, la ciudad fue objeto de importantes inversiones urbanísticas:

a) Reordenación urbana: se procedió a la reforma y ampliación de ocho calles, situadas en el centro de la urbe.

b) Nuevas construcciones y reformas: entre ellas destaca la construcción de un hospital para dementes en 1409 y de una nueva sala para las reuniones del Consell en $1428^{12}$, a lo que debemos añadir el nuevo almudín, la lonja del mustassaf, la cárcel común y el mercado ${ }^{13}$.

Pero mayor interés revisten las inversiones relacionadas con la infraestructura comercial:

a) El Grau: Esta población arranca del período postconquista y antes de 1249 ya disponía de un circuito amurallado ${ }^{14}$. La vida de esta población, rodeada de marjales, no debió ser demasiado próspera puesto que en 1401 los Jurados estimulaban su repoblación ". En 1338, el Consell ordenó la construcción de una alhóndiga para custodiar aparejos de naves ${ }^{16}$. Después, a principios del siglo XV, la población fue dotada de agua potable -para ello los Jurados impusieron 12.000 sueldos de censales- ${ }^{17}$, en parte destinada al servicio de los buques per prende ayguades.

b) Las atarazanas: en el siglo XIII y principios del siglo XIV consta la presencia de una atarazana extramuros de la ciudad y que pertenecía a los pescadores, y de una atarazana real, que se encontraba en el Grau y está documentada en 1324, aunque posiblemente sea de época anterior ${ }^{18}$.

La política mediterránea de los reyes de Aragón -conquista de Cerdeña, guerra con Génova- involucra a Valencia en las expediciones navales de la época, determi208.

1 C. SANCHEZ CUTILLAS, La fabrica volla de murs e valls, «VIII CHCA* (Valencia, 1970), II, p. $207-$

12 A. SANTAMAŔ́, Aportación al estudio de la economia de Valencia durante el siglo XV, Valencia, Instituto «Alfonso el Magnánimow, 1966, p. 45 y 47.

13 A. CUEVES GRANERO, Problemas valencianos do los primeros años del reinado de Alfonso V, "IV CHCA* (Palma de Mallorca, 1959), I. p. 459.

14 A. JANINI DE LA CUESTA. El justicia y las atarazanas dol Graw de la mar de Valencia a principios del siglo XIV, «VIII CHCA», II, p. 244, nota 4.

is J. HINOJOSA, La estructura urbana del nimo. Las obras priblicas, «Nuestra Historia», III (Valencia, 1980), p. 232.

16 V. BOIX, Historia do la ciudad y mino do Valencia, Valencia, 1845, p. 427.

17 J. GUIRAL, L'Guolution dx paysage urbain à Valencia ds XIII as XVI sizcle, «La ciudad hispánica durante los siglos XIII al XVI», Madrid, Universidad Complutense, 1985, II. p. 1599.

18 A. GARCía SANZ, Historia do la marina catalana, Barcelona, Ed. Aedos, 1977, p. 81. 
nando la necesidad de una atarazana municipal; de ahí que el Consell, en 1338, acordara la construcción de tales instalaciones. El proyecto no fue adelante, puesto que en 1410 vuelve a replantearse; en dicha fecha el Consell acordaba construir una atarazana de pedra e arcs bellament en lo Grao ${ }^{19}$. Al parecer, tampoco esta vez llegaron a construirse las atarazanas municipales, debiendo esperarse a la época del redres de Fernando el Católico.

c) El puerto; las condiciones de la costa del Grau no eran las más idóneas para la construcción de un muelle artificial -como el que disponía la Ciudad de Mallorca desde el siglo XIII- debido a la cercanía del río Turia y a las peligrosas corrientes marinas. Sin embargo, sorprende la falta de iniciativas que traten de subsanar estos inconvenientes. Baste recordar que, en 1438, Alfonso V concedió a Barcelona la facultad de construir un muelle artificial.

\section{PROBLEMAS DEFENSIVOS}

La piratería y el corsarismo habían venido cobrando importancia desde el último cuarto del siglo anterior. Es cierto que desde Mallorca se producen réplicas como la armada contra Giger en $1377^{20}$ o como la Armada Santa, en la que participa Valencia, de 1398, ambas con resultados muy inciertos.

Ahora, sin embargo, la penuria financiera de la Universidad de Mallorca, al debilitar la capacidad defensiva del reino, la expone a riesgos importantes.

La campaña de Cerdeña tiene por efecto activar en las Baleares el corsarismo genovés al que se une el ya tradicional corsarismo musulmán. Poco después, la lentitud en la resolución de la problemática sucesoria de Martín el Humano ofrece al corsarismo una coyuntura excelente para incrementar su agresividad.

Defender la isla con eficacia suponía inversiones considerables y el margen de maniobra de la Universidad de Mallorca era reducido: derrama de un impuesto directo (una talla), incremento de las ayudas existentes -los llamados afitons - para avalar emisiones de nueva deuda, suspensión temporal del pago de la deuda, recuperación de deudas antiguas. Las alternativas mencionadas resultaban, sin embargo, igualmente conflictivas. El sistema de gravamen directo tenía el apoyo, en ciertas condiciones, de los menestrales y los foráneos y la oposición de los demás estamentos, y actitudes inversas se producían respecto a los impuestos indirectos. La suspensión del pago de la deuda pública tenía consecuencias obvias y sólo podía establecerse en caso de extrema necesidad, y recuperar deudas antiguas era empresa poco menos que imposible. En resumen, la maniobrabilidad financiera de la Universidad era prácticamente insignificante y siempre conflictiva.

Por esto, los Consells Generals de este período, que tratan temas financieros, acaban normalmente con la consabida falta de acuerdo y su aplazamiento para posteriores sesiones. Al final, sin embargo, solían imponerse las tesis de incrementar los gravámenes ya existentes.

19 R. FERRANDO PÉREZ y J. SANCHEZ ADELL, Las atarazanas de Valoncia, «Saitabi», 5 (1947), p. 63.

20 P. CA TEURA, Política y finanzas del reino de Mallorca bajo Pedro IV de Aragón, Palma de Mallorca, Institut d'Estudis Baleàrics, 1982, p. 177. 
En 1410, la Universidad disponía de cuatro galeras de tonelaje y estado diversos; parte de ellas habían participado en la operación de Cerdeña ${ }^{21}$ y en abril del año indicado se encontraban ya de regreso en Mallorca. En una sesión del Consell General, celebrada el mismo mes, se discutió si dichas naves debían dejarse ancladas en Portopí, dada la proximidad del verano, o vararlas en la atarazana ${ }^{22}$; no se tomó acuerdo al respecto, remitiéndose a los Jurados; éstos, en una nueva sesión, propusieron prestar dichas naves, lo cual fue aprobado bajo las siguientes condiciones:

a) Se prestaban dos galeras de la Universidad a Pelayo Unís, Macià Borrassà y Bartomeu Fuster.

b) De las cuatro galeras de la Universidad, los indicados no podrían tomar la mejor sino escoger entre las tres restantes.

c) Los interesados deberían reparar, armar y devolver dichas naves a dique seco a sus propias expensas. naves ${ }^{23}$.

d) Los prestatarios estaban obligados a patronejar e anar personalment dichas

El préstamo de las galeras mencionadas tiene un interés doble. Pelayo Unís no era un simple particular sino el lugarteniente de Mallorca y, dado que el gobernador titular Roger de Moncada se encontraba fuera de la isla desde 1408, Unís ejercía de hecho como gobernador. Por consiguiente, se trata en cierta forma de una cesión institucional, cercana al espíritu de los pactos del pariaje de 1316, pues está destinada a resolver un problema defensivo.

La operación, por otra parte, resolvía a la Universidad de Mallorca el problema financiero de armar buques para la defensa costera, cuestión nada trivial dada la situación existente.

La política de Alfonso $\mathrm{V}$ involucra de nuevo a Mallorca y Valencia en los conflictos mediterráneos. En 1420, el rey organizó una expedición a Cerdeña; hizo escala en Mallorca el 17 de mayo, permaneciendo dos semanas en la isla. De ahí, la puesta en práctica de una serie de medidas encaminadas a robustecer su capacidad defensiva frente al corsarismo genovés:

a) Sector del muelle: se asignan 300 libras para distintas obras de reforzamiento del muelle, encargándose su gestión al mercader Pere Gual. A su vez, se procedió a artillar la torre de la font del moll ${ }^{24}$.

b) Sector de Portopí: las obras documentadas pertenecen a 1421 y consistieron en montar un trabucb y artillar sus torres con bombardas.

Complementariamente, se concedieron licencias de corso contra genoveses en junio de 1420 y se construyó una galera ${ }^{23}$.

Los problemas defensivos eran, si cabe, más graves en Valencia debido al corsarismo castellano y musulmán. Está documentada la concesión de 198 licencias de armamento entre 1409 y $1420^{26}$. En esta última fecha, el municipio decidió

21 ARM, AGC 2, fol. 21 r.

22 Id, id, fol. 18 v.-19 r.

23 Id, id, fol. 33 v. -34 r.

24 ADM, MSL/a 87, fol. s/f.

25 A. CAMPANer, Cronicón mayoricense, Palma de Mallorca, 1967, p. 193 y ADM, MSL/a 87, fol. 1r.-5r.

26 A. SANTAMARÍA, Op. cit., p. 109. 
organizar una flota -la integraban dos naves, dos galeras, un ballenero y otras embarcaciones menores- para que actuara contra los genoveses. Después, en 1424, se proyectó una armada en la que debían participar Valencia, Barcelona, Mallorca, Perpiñán, Tortosa y las Órdenes Militares contra los corsarios ${ }^{27}$.

\section{PROBlemas PINANCIEROS EN VALENCiA}

Durante las primeras décadas del siglo XV Valencia subvenciona a la monarquía con préstamos -cuya secuencia comienza en 1426- y con subsidios -entre 1417 y 1419 el municipio abona al rey 1.210 .000 sueldos- ${ }^{28}$. Este hecho, unido a la política de obras públicas y la política defensiva, determina un cierto endeudamiento de la ciudad:

$\begin{array}{ll}1400-1401 & 18.042 \text { libras } \\ 1409-1410 & 22.397 " \\ 1420-1421 & 25.453 " \\ 1430-1431 & 28.230 \ll\end{array}$

Como vemos, en treinta años los intereses se habían incrementado en diez mil libras, de ahí la toma de medidas destinadas a disminuir la carga financiera de la deuda pública:

a) Ya en 1409 el Consell decide reducir el interés de las pensiones entre medio punto y un punto, pasando del $7,7 \&$ y del $7,2 \%$ al $6.7 \%$.

b) En 1428, se tomó el acuerdo, no cumplido, de no otorgar más préstamos al rey, dictándose normas de amortización de la deuda.

c) Finalmente en 1434, cuando los intereses anuales de la deuda alcanzaban ya la cifra de 31.608 libras, una comisión presidida por los Jurados acordó un plan de cuatro puntos, sancionado por la Pragmática de 1435: reducción de los gastos ordinarios, medidas contra morosos, revisión de cuentas y plan de amortización de la deuda pública.

Dicho plan debía tener una vigencia de diez años ${ }^{30}$ y tuvo la virtualidad de congelar la deuda -en 1445, la deuda había quedado estabilizada en 31.991 libras-, aunque no se consiguió disminuirla; acaso por esta razón, Alfonso $\mathrm{V}$ procedió a renovar la Pragmática de amortización cuando se cumplía el plazo de vigencia. El plan funcionó ya que se consiguió estabilizar la deuda; en el período de 1452-1453, los intereses de la deuda se habían situado en 29.767 libras ${ }^{31}$.

Como consecuencia del plan de amortización se consignaron a su pago ingresos comerciales, como los dos diners per lliura de la mercaderia y los dos diners de la carn.

27 C. CARRÈre, Bancelome, conino ́́conomique, 1380-1462, Paris, Mouton, 1967, II. p. 763.

28 A. SANT AMARIA, Op. cit., p. 58.

29 E. BelengUeR, Valincia on la misi del sogle XV, Barcelona, Edicions 62, 1976, p. 58.

30 A. SANTAMARIA, Op. cit., p. 73.

31 E. BELENGUER, Op. cit., p. 58. 


\section{CRISIS FINANCIERA EN MALLORCA}

$\mathrm{El}$ incremento de gastos hace resurgir nuevamente la polémica sobre financiación, ya que con los fondos disponibles la Universidad de Mallorca no podía seguir afrontando sus compromisos.

El problema, dado el contexto político del momento, era difícil de resolver. Los afitons de los impuestos indirectos no admitían ya más sobretasas y, aunque se impusieran en algún caso, su rendimiento no resolvería la cuestión. Quedaban, entonces, las tres alternativas ya conocidas. Se encontraba en primer lugar la talla; en 1422 se acordó derramar este impuesto directo por un importe global de 12.000 libras, pero la oposición de ciertos grupos frustró de momento la iniciativa. $\mathrm{Al}$ año siguiente volvió a plantearse la necesidad de imponer una talla, ahora por valor de 25.000 libras, para poder cubrir todos los gastos pendientes ${ }^{32}$.

El plan previsto, que contaba con el respaldo del gobernador, consistía en gravar las fortunas de todos los habitantes de la isla, con independencia del lugar de residencia (desde 1315 regía el sistema de que la ciudad corría con las $2 / 3$ partes de los impuestos generales y los campesinos con el resto). Por distintas razones la oposición al proyecto resultó generalizada y por ello al final la talla no se recaudó, pese a que los foráneos, presionados por el gobernador, habían procedido a cuotar las distintas villas. Por esto, la situación financiera de la Universidad presentaba el siguiente aspecto en el período de 1425-1426 "3:

Ingresos totales
(VII.1425-VI-1426)
$\begin{aligned} & \text { Pagos de pensiones de } \\ & \text { deuda (mismo período) }\end{aligned}$

Tales cifras nos explican el por qué la Universidad decidió suspender el pago de pensiones a los barceloneses (sólo se llegó a pagarles 6.207 libras), dando esta vez prioridad a los acreedores mallorquines.

\section{La CONStrucción de la lonja de Palma}

En este contexto -el cese del pago de intereses a los catalanes se mantuvo hasta 1431- se produce un hecho importante: la construcción de la Lonja. La iniciativa de la obra fue, por supuesto, de los deffenedors de la Mercaderia, pero no se entiende su puesta en práctica sin el apoyo de la Universidad, de sectores sociales influyentes e incluso el papel que posiblemente jugó la monarquía.

La Universidad percibía dos tributos típicamente comerciales: el llamado entrada e exida de navilis y el victigal o diner de la mercaderia. El primero era de

32 A. SANTAMARfa, El mino de Mallonca..., pp. 89-97.

33 M. VALIS BERTRAND, Sistoma fuscal y douda pública do Mallonca (1425-1426), Memoria inédiea de licenciatura, Facultead de Filosofia y Letras de Palma de Mallorca, 1985, pp. 144, 190 y 193. 
escasa cuantía anual -unas cien libras aproximadamente, aunque con los atrasos podía llegar a triplicarse-, mientras que el segundo era considerable - 1.603 libras en el período mencionado, aunque sumando los atrasos se alcanzaron $2.864 \mathrm{li}$ bras ${ }^{34}$.

Poco antes de 1426 la Universidad decidió la transferencia temporal de dicho victigal a los mercaderes con la finalidad de financiar las obras de la Lonja, pensada como sede de la contratación comercial y residencia del Col legi de la Mercaderia y del Consulado de Mar.

En marzo de 1426, los deffenedors Francesc Anglada y Joan Terriola -este último era también consejero del Consell General- ${ }^{35}$ firmaban el contrato de construcción de la Lonja con el maestro Guillem Sagrera, estipulando lo siguiente:

a) Guillem Sagrera debería terminar la obra en el plazo de 15 años (cubrirla al cabo de 12 años y el resto del tiempo invertirlo en las demás obras secundarias).

b) Se señalaban algunos de los materiales a utilizar, así como otras características arquitectónicas y de decoración escultórica.

c) El presupuesto de la obra se fijaba en 22.000 libras. Cada año los gerentes de la obra le entregarían la integridad de los fondos del victigal, salvo 150 libras destinadas a gastos ordinarios del Col legi ${ }^{36}$.

En 1431, se produjo la llamada Concordia de Barcelona, según la cual volvieron a vincularse al pago de la deuda totes e sengles imposicions, victigals, e drets qualsevols imposats e imposadors de e sobre la dita Universitat ${ }^{37}$.

De cumplirse la normativa, había que proceder al cese de las obras de la Lonja. Desconocemos los acuerdos concretos que se tomaron; sin embargo informaciones posteriores nos indican que el Col-legi emitió deuda pública y que ésta no había sido amortizada todavía en $1440^{38}$.

Dichas emisiones permitieron incluso, en 1433, reconstruir cerca de la Lonja el moll o pont de fusta de la mercaderia, embarcadero que databa de principios del siglo XIV. Algunos años más tarde se procedió a reordenar la zona de la Lonja, especialmente las murallas colindantes.

\section{ABANDONO DE LAS INSTALACIONES PORTUARIAS DE MALLORCA}

Otro tema importante era el mantenimiento del muelle. En 1440, prácticamente terminadas las obras de la Lonja salvo algunos detalles, los deffenedors urgían la reparación del muelle, com sia en punct de destrucció, ya que el impuesto llamado mollatge estaba vinculado al pago de la deuda pública. El Consell General acordó solicitar la autorización del rey para desvincular el impuesto y asignarlo a la financiación de dicha obra, pero la oposición de los acreedores impidió la mencionada transferencia ${ }^{39}$.

34 Id, id, p. 79 y 82.

3s ARM, E.U. 3, fol. 343 r.

36 A. FRAU, La Lonja de Palma, «BSAL», I (1885-1886), núm. 14, pp. 2-3.

37 A. SANTAMARIA, El reino de Mallorca..., p. 142.

38 A. CAMPANER, Op. cit., p. 163.

39 ARM, AGC 3, fol. 75 v.-77 r. 
En lo sucesivo, la política de los deffenedors se centrará precisamente en este tema, el de conseguir una financiación estable para la conservación del muelle y de Portopí. El muelle era motivo objetivo de preocupación: desde 1447 a 1451 fue utilizado como depósito de piezas de piedra con destino a las obras de Castelnuovo de Nápoles, sólo en 1451 se envió una remesa de 1.556 piezas ${ }^{40}$.

Pero en 1450 estallaba la revuelta campesina de los foráneos, prolongándose hasta 1453. Después fueron otras las cuestiones prioritarias que debieron atenderse; en efecto, durante la revuelta los Jurados habían tomado 50.000 libras del fondo de la Consignación y además Alfonso V exigía 20.000 ducados como pago de las tropas enviadas para reprimir el movimiento, por lo que la Universidad se encontraba en virtual bancarrota ". En 1454, tuvo que acordarse un plan de reducción de gastos y se suspendió la amortización de la deuda, que, con distintas incidencias, venía realizándose a un ritmo de 10.000 florines desde 1431 , pactándose nuevamente en 1459 con los acreedores catalanes el pago de la deuda pendiente ${ }^{42}$.

En esta coyuntura, poca era la atención que podía dispensarse a las instalaciones portuarias, aunque éstas, en su mayor parte, requerían una urgente intervención. Desde 1452 son frecuentes las instancias solicitando el dragado de Portopí ${ }^{43}$ y la reparación de sus torres, la reconstrucción del muelle, arruinado por los temporales y su indiscriminado uso, y la restauración de la atarazana.

La Universidad se fue haciendo cargo de tales obras, aunque lentamente y destinándoles un corto presupuesto. En 1454, los Jurados acordaron destinar una pequeña cantidad -100 libras- al muelle y a la zona de muralla de Santa Catalina ${ }^{44}$. Terminadas las obras, volvió a renovarse la prohibición de descargar en él materias pesadas, salvo por necesidades de la Universidad y del Col.legi de la Mercaderia ${ }^{4}$.

El dragado de Portopí era empresa más costosa y precisamente por esto las repetidas gestiones de los deffenedors chocaban con el consabido no hay dinero de los Jurados. Los mercaderes se dirigieron, entonces, al rey para que presionara a los mismos. La ordenanza real se publicó finalmente en 1458 , recomendando la devolución del mollatge al Col· legi ${ }^{46}$. La respuesta del Consell General fue un tanto dilatoria al nombrar una comisión que estudiara el tema de la devolución de dicho impuesto. El informe jurídico debió tardar en presentarse o al menos no consta su aprobación, pues más de un año después los mercaderes seguían insistiendo en el tema ${ }^{4}$.

Las torres de Portopí y la atarazana se encontraban en peor situación. En 1456, los mismos Jurados reconocían que les torres de Portopí són en gran perill de caure y sin embargo nada se hizo para subsanarlo. Lo propio sucedía con la atarazana, con el

40 A. CAMPANER, Op. cit., p. 211.

41 ARM, AGC 7, fol. 73 r. -84 r.

42 Id, id, fol. 94 r. -96 r.

43 ARM, AGC 5, fol. $58 \mathrm{r}$.

44 A. PONS PASTOR, Documenta, «BSALw, XXVI (1935-1936), p. 211.

4s $A R M, ~ \triangle G C ~ 7$, fol. 112 v.

46 F. Sevillano Colom y J. POU, Op. cit., p. 143.

47 ARM, AGC 7, fol. 96 v.-107 r. 
agravante de que la Universidad se vio envuelta en un pleito con el guarda por el que éste reclamaba 800 libras en concepto de salarios atrasados ${ }^{40}$.

\section{CONCLUSIÓN}

La primera mitad del siglo XV en Mallorca transcurre entre dos polos: la quiebra financiera de 1405 y la revuelta foránea de 1450 . Estos dos hechos determinan que la Universidad no pueda atender una política de realizaciones infraestructurales, salvo el caso de la Lonja, y que se limite al mantenimiento, siempre precario, de las instalaciones heredadas del siglo anterior.

El caso de Valencia es casi opuesto. La política de saneamiento financiero emprendida en 1434-1435 logra congelar la deuda en niveles bastante moderados durante veinte años. Este hecho y el dinamismo de su economía permiten al municipio afrontar una política de obras públicas centrada en la remodelación urbanística y en la proliferación de construcciones de carácter administrativo y asistencial.

PAU CATEURA BENNASSER Universidad de las Islas Baleares

4. ARM, AGC 6, fol. 94 r. -97 r. 